\title{
Erythrocyte Glutathione Synthetase Deficiency Leads Not Only to Glutathione but Also to Glutathione-S-Transferase Deficiency
}

Ernest Beutler, Terri Gelbart, and Charles Pegelow

Department of Basic and Clinical Research, Scripps Clinic and Research Foundation, La Jolla, California 92037; and Department of Pediatrics, University of Miami School of Medicine, Miami, Florida 33101

\begin{abstract}
Glutathione synthetase (GSH-S) is one of the two known hereditary causes of glutathione deficiency. We describe a family whose two children have hemolytic anemia. The children's erythrocytes lack GSH and are severely deficient in GSH-S activity. No neurologic findings or 5-oxoprolinuria were present. A concurrent deficiency of glutathione-S-transferase (GST) was also detected in the erythrocytes. Residual glutathione could be detected in the erythrocytes using a sensitive cycling assay. The deficiency was found to be most severe in reticulocyte-depleted preparations. The GSH-S activity of the erythrocytes of the parents was one-half normal, while the glutathione S-transferase activity was normal. We conclude that the primary defect is one of GSH-S. Glutathione stabilizes GST in vitro, and it is assumed that the deficiency of GST in the erythrocytes of the patients is due to the instability of this enzyme in the absence of adequate intracellular GSH levels.
\end{abstract}

\section{Introduction}

A variety of methods have been devised to deplete cells of glutathione (1-3), but none is as informative as hereditary defects in synthesis of this tripeptide. Reduced glutathione (GSH) is synthesized in two steps. First, a peptide bond is formed between the $\gamma$-carboxyl group of glutamate and the amino group of cysteine to form the dipeptide, $\gamma$-glutamyl-cysteine. This reaction is catalyzed by the enzyme $\gamma$-glutamyl-cysteine synthetase (GC$S)$. Then, the formation of a peptide bond between $\gamma$-glutamyl cysteine and glycine is catalyzed by a second enzyme, glutathione synthetase (GSH-S). ATP serves as a source of energy for both reactions. They may be summarized as follows:

glutamate + cysteine + ATP $\stackrel{\text { GC-S }}{\longrightarrow}$ $\gamma$-glutamyl-cysteine + ADP

$\gamma$-glutamyl-cysteine + glycine + ATP $\stackrel{\text { GSH-S }}{\longrightarrow}$ GSH + ADP

Inherited deficiencies of each of these enzymes have been reported. Both are very rare and result in GSH deficiency. Glutathione deficiency has been associated with nonspherocytic hemolytic anemia and, in some instances, with other disturbances, including neurological disorders and metabolic acidosis.

This manuscript is publication no. 3946BCR from the Research Institute of Scripps Clinic.

Received for publication 29 July 1985.

J. Clin. Invest.

(c) The American Society for Clinical Investigation, Inc.

0021-9738/86/01/0038/04 \$1.00

Volume 77, January 1986, 38-41
We have now had the opportunity to study two sibs with hemolytic anemia associated with a severe deficiency of erythrocyte GSH. The erythrocytes of these children were found to be deficient both in GSH-S and in glutathione-S-transferase (GST). ${ }^{1}$ We provide evidence that the latter enzyme deficiency is secondary to the decreased levels of GSH in the erythrocyte, and that the primary defect is one of GSH-S activity.

Clinical history. Lazardo V. is a 13-yr-old boy born in Cuba to parents who are first cousins. No medical problems were noted until 1981 when he was 9-yr-old. At this time, he was found to have a hemolytic anemia. The hemoglobin concentrations ranged between 9 and $11 \mathrm{~g} / \mathrm{dl}$ and uncorrected reticulocyte counts between 2 and 14\%. The erythrocyte indices and morphology were normal. The Coombs test was negative and hemoglobin electrophoresis was normal.

Physical examination was normal. Specifically, no neurologic defect was found. He experienced normal growth and development. At the time of his last examination his height was at the 5 th and his weight at the 25 th percentile. He attends public school where he is a B student in the seventh grade.

Luis V. is the 8-yr-old brother of Lazardo V. He was similarly not known to have any medical abnormality until his hemolytic anemia was discovered in 1981 . Hematologic values have been similar to those of his brother. Physical and neurologic examinations were normal. At his last examination, his height was below the 5th and his weight at the 10th percentiles. He was reported to have some minor behavioral problems at school and at home, and receives grades of $\mathrm{C}$ and $\mathrm{D}$ in the third grade.

\section{Methods}

Blood samples for enzyme assays were drawn into EDTA anticoagulant, $\sim 1 \mathrm{mg} / \mathrm{ml}$ blood, and shipped on ice by air to La Jolla for assay. All measurements were carried out within $4 \mathrm{~d}$ of the time the blood was drawn. Blood for the determination of metabolic intermediates was deproteinized with perchloric acid immediately upon drawing and neutralized (4) before shipment.

Enzyme assays were carried out as previously described (4). GSH-S activity was measured by our modification (5) of the method of Minnich et al. (6). GC-S activity was measured by estimating, by means of the pyruvate kinase reaction, the formation of ADP in a system containing hemolysate, ATP, cysteine, and glutamate. Representing a modification of the system described by Foure-Seelig and Meister (7), the complete assay system contained $100 \mu \mathrm{mol}$ Tris- $\mathrm{HCl}$ ( $\mathrm{pH} \mathrm{8.0),} 0.5 \mu \mathrm{mol}$ EDTA, $100 \mu \mathrm{mol} \mathrm{KCl}, 20 \mu \mathrm{mol} \mathrm{MgCl}, 2 \mu \mathrm{mol} \mathrm{ATP}, 0.2 \mu \mathrm{mol} \mathrm{NADH}, 2.5$ $\mu \mathrm{mol}$ phosphoenolpyruvate, $10 \mu \mathrm{mol}$ each cysteine and glutamic acid, $0.5 \mathrm{U}$ each of pyruvate kinase and lactate dehydrogenase, and $50 \mu \mathrm{l}$ of a 1:10 stroma-free hemolysate in a total volume of $1 \mathrm{ml}$.

GSH estimations were performed using 5,5'-dithiobis(2-nitrobenzoic acid) (DTNB) (8). In some instances the concentration of total glutathione

1. Abbreviations used in this paper: DTNB, 5,5'-dithiobis(2-nitrobenzoic acid); GC-S, $\gamma$-glutamyl-cysteine synthetase; GSH, glutathione; GSH-S, glutathione synthetase; GST, glutathione-S-transferase; $\mathrm{Hb}$, hemoglobin. 
(oxidized + reduced) was determined by enzymatic cycling using our modification (8a) of the methods of Owens and Belcher (9) and of Tietze (10). Levels of metabolic intermediates were estimated fluorometrically and spectrophotometrically as previously described (4).

Density separation of erythrocytes into light (reticulocyte-enriched) and dense (reticulocyte-poor) fractions was achieved using Percoll-Hypaque (11).

Urinary 5-oxoproline was determined by measuring the glutamic acid concentration before and after acid hydrolysis of 5-oxoproline to glutamic acid. Urine samples were passed through a UM2 filter (Amicon Corp., Scientific Systems Div., Danvers, MA). After acidification with acetic acid to $\mathrm{pH}$ of 3.0 they were applied to a $1 \times 6 \mathrm{~cm}$ Dowex 50 (hydrogen cycle) column (Bio-Rad Laboratories, Richmond, CA) that had been equilibrated with $1 \%$ acetic acid. The sample was washed through the column with $6 \mathrm{ml}$ of $1 \%$ acetic acid and brought to a final volume of $10 \mathrm{ml}$ after neutralization with sodium hydroxide. Two 200 $\mu l$ aliquots of each column effluent were dried. One was hydrolyzed at $110^{\circ} \mathrm{C}$ with $6 \mathrm{~N} \mathrm{HCl}$ for $20 \mathrm{~h}$; the others served as a nonhydrolyzed control. The concentration of glutamic acid was measured on a $121 \mathrm{M}$ amino acid analyzer (Beckman Instruments, Inc., Spinco Div., Palo Alto, CA).

\section{Results}

The activities of erythrocyte enzymes of the patients and their parents are presented in Table I. The activities of GSH-S and of GST were markedly diminished, but the activity of GC-S was normal. Very significantly, the activity of GSH-S was about onehalf normal in both parents, but the activity of GST was normal in the parents. As expected in children with an elevated reticulocyte count, the levels of some of the age-related enzymes were increased in the patients.

Levels of metabolic intermediates are shown in Table II. It is apparent that both children had a profound deficiency of erythrocyte GSH. The amount of GSH in the erythrocytes was sufficiently low so as to be at the limit of detection by the DTNB method. For this reason the level of total glutathione was also estimated by enzymatic cycling, a technique that is several orders of magnitude more sensitive than the DTNB method. The application of this technique confirmed that glutathione was, indeed, present in the erythrocytes of the deficient patients.

Estimation of the levels of glutathione in reticulocyte-enriched and reticulocyte-depleted fractions of erythrocytes indicated that most of the residual glutathione was in the younger cells, and that these cells had an increased amount of residual GSH-S and GST activity (Table III).

Leukocyte glutathione levels were also measured in the patients, their mother, and a concurrent normal control. Because of the small amount of blood available for study, only a mixed leukocyte fraction isolated by discontinuous density gradients of Ficoll-Hypaque (12) could be assayed. The amount of glutathione expressed as micromoles per gram protein found by enzymatic cycling was 11.8 and 9.5 in the two patients, 10.7 in the mother, and 10.0 in the concurrent control. The urinary 5oxoproline level of Lazardo V. was $424 \mu \mathrm{M}$. A control sample contained $541 \mu \mathrm{M}$ 5-oxoproline.

Table I. Activities of Erythrocyte Enzymes of the Patients and their Parents

\begin{tabular}{|c|c|c|c|c|c|c|}
\hline Enzyme & Normal range & Luis $\mathbf{V}$. & Lazardo V. & Mother & Father & Control \\
\hline & $I U / g H b$ & & & & & \\
\hline Hexokinase & $1.0-2.5$ & 2.1 & 2.2 & & & \\
\hline Glucose phosphate isomerase & $38.8-82.8$ & 52.5 & & & & \\
\hline Phosphofructokinase & $7.5-15.0$ & 10.5 & & & & \\
\hline Aldolase & $1.5-4.9$ & 4.3 & & & & \\
\hline Triose phosphate isomerase & $1,317.0-2,905.0$ & $1,582.0$ & & & & \\
\hline Glyceraldehyde phosphate dehydrogenase & $142.2-309.8$ & 197.7 & & & & \\
\hline Diphosphoglycerate mutase & $3.5-6.1$ & 5.3 & & & & \\
\hline Phosphoglycerate kinase & $247.8-392.2$ & 250.4 & & & & \\
\hline Monophosphoglycerate kinase & $26.6-48.8$ & 24.5 & & & & \\
\hline Enolase & $3.7-7.0$ & 7.4 & & & & \\
\hline Pyruvate kinase & $11.1-18.9$ & 18.3 & & & & \\
\hline Lactate dehydrogenase & $147.0-253.0$ & 158.1 & 184.6 & & & \\
\hline Glucose-6-phosphate dehydrogenase & $7.9-16.3$ & 12.9 & 13.5 & & & \\
\hline 6-Phosphogluconate dehydrogenase & $7.2-10.3$ & 9.9 & 9.0 & & & \\
\hline \multicolumn{7}{|l|}{ Glutathione reductase with flavin adenine } \\
\hline dinucleotide & $7.4-13.4$ & 7.9 & 10.8 & 11.3 & 9.8 & 9.0 \\
\hline Glutathione peroxidase & $21.4-40.3$ & 14.1 & 22.1 & 24.8 & 20.4 & 30.3 \\
\hline Adenylate kinase & 199.4-316.6 & 240.8 & & & & \\
\hline \multicolumn{7}{|l|}{ Glutamate-oxaloacetate transaminase with } \\
\hline pyridoxal-5'-phosphate & $3.2-6.8$ & 12.6 & 8.6 & & & \\
\hline Glycerophosphate dehydrogenase & $0.0-0.0$ & 0.0 & & & & \\
\hline Pyrimidine 5'-nucleosidase & $100.5-176.1$ & 264.2 & & & & \\
\hline Adenosine deaminase & $0.7-1.6$ & 0.7 & & & & \\
\hline GST & $3.0-10.3$ & 0.9 & 0.7 & 3.3 & 4.2 & 3.8 \\
\hline GSH-S & $0.12-0.19$ & 0.0013 & 0.0025 & 0.072 & 0.066 & 0.13 \\
\hline GC-S & $0.39-0.91$ & 1.39 & 1.45 & 0.93 & 0.81 & 0.85 \\
\hline
\end{tabular}


Table II. The Levels of Metabolic Intermediates in Erythrocytes of Patients, Family Members, and a Concurrent Control

\begin{tabular}{|c|c|c|c|c|c|c|}
\hline & Normal range & Luis V. & Lazardo V. & Mother & Father & Control \\
\hline $\mathrm{GSH}^{*}(\mu \mathrm{mol} / \mathrm{g} H b)$ & $4.5-8.7$ & 0.22 & 0.24 & 6.1 & 5.8 & 5.3 \\
\hline $\mathrm{GSH} \ddagger(\mu \mathrm{mol} / \mathrm{g} \mathrm{Hb})$ & & 0.10 & 0.10 & 5.4 & & 4.9 \\
\hline ATP $(\mu m o l / g H b)$ & $3.7-4.8$ & 4.8 & 4.3 & 3.6 & 3.1 & 3.1 \\
\hline 2,3-DPG $(\mu \mathrm{mol} / \mathrm{g} H b)$ & $8.5-16.0$ & 15.2 & 16.1 & 10.2 & & 9.7 \\
\hline G-6-P $(n m o l / g H b)$ & $38-126$ & 62.3 & 39.6 & 28.6 & & 24.8 \\
\hline F-6-P $(n m o l / g H b)$ & $15.4-38.6$ & 22.6 & 20.8 & 10.8 & & 10.0 \\
\hline DHAP $(n m o l / g H b)$ & $11.2-44.0$ & 8.2 & 9.4 & 6.0 & & 5.7 \\
\hline FDP $(n m o l / g H b)$ & $2.0-9.2$ & 3.4 & 4.5 & 2.1 & & 2.8 \\
\hline PEP $(n m o l / g H b)$ & $23.0-48.8$ & 23.7 & & & & 12.4 \\
\hline 2-PGA $(\mathrm{nmol} / \mathrm{g} \mathrm{Hb})$ & $0.8-36.2$ & 5.0 & & & & 4.6 \\
\hline
\end{tabular}

Abbreviations used in this table are: DHAP, dihydroxyacetone phosphate; 2,3-DPG, 2,3-diphosphoglycerate; F-6-P, fructose-6-phosphate; FDP, fructose diphosphate; G-6-P, glucose-6-phosphate; PEP, phosphoenolpyruvate; 2-PGA, 2-phosphoglyceric acid. * Whole blood assay. $¥$ Cycling assay on washed leukocyte-free erythrocytes.

\section{Discussion}

GSH-S deficiency presents as two quite distinct clinical syndromes. The more severe of these is characterized by 5-oxoprolinuria, metabolic acidosis, and a neuromuscular disorder. Interestingly, although this syndrome was first reported in 1970 (13) it was not until four years later that the lack of glutathione in erythrocytes (14) and the basic enzymatic defect (15) was appreciated. Since this time, several similar additional cases have been documented (16-20). Erythrocyte glutathione deficiency unaccompanied by neurologic defects was first reported by Oort et al. in 1961 (21). A few additional cases of erythrocyte GSH$\mathrm{S}$ deficiency without systemic symptoms have been reported subsequently $(22,23)$. The present cases appear to be only the fourth family with GSH-S deficiency causing hemolytic anemia without neurologic disease. The urinary 5-oxoproline level in one other such patient has been measured (24) and, as in our case, was found to be normal. This finding implies that the erythrocyte, the only tissue presumably involved in this type of GSH-S deficiency, does not represent an important source of 5-oxoproline.

Table III. Reticulocyte Counts and Some Biochemical Parameters in Centrifuged Erythrocytes

\begin{tabular}{lclll}
\hline & Reticulocyte & GSH & GSH-S & GST \\
\hline & $\%$ & $\mu m o l / g ~ H b$ & $I U / g ~ H b$ & $I U / g ~ H b$ \\
Luis V. & & & & \\
$\quad$ Reticulocyte enriched & 22.8 & 1.53 & 0.023 & 1.43 \\
$\quad$ Reticulocyte depleted & 0.2 & 0.03 & 0.0013 & 0.56 \\
Lazardo V. & & & & \\
$\quad$ Reticulocyte enriched & 20.6 & 1.10 & 0.023 & 2.63 \\
Reticulocyte depleted & 0.3 & 0.02 & 0.0025 & 0.44 \\
Mother & & & & \\
$\quad$ Reticulocyte enriched & 4.4 & 5.21 & 0.076 & 3.90 \\
Reticulocyte depleted & 0.1 & 4.90 & 0.077 & 3.15 \\
Control & & & & \\
Reticulocyte enriched & 4.1 & 5.37 & 0.128 & 3.71 \\
Reticulocyte depleted & 0.2 & 5.12 & 0.151 & 3.14 \\
\hline
\end{tabular}

It was conjectured that the two very different clinical presentations characteristic of GSH-S deficiency might be due to differences in tissue distribution of the defect (25) and this suggestion was verified in one previously studied case (24). The leukocytes of our patient had normal enzyme activity. It is interesting to speculate how such differences in tissue distribution of enzyme deficiencies may come about. Tissue-specific isozymes can be one explanation. Another is the susceptibility of mutant enzymes to proteases that are present only in the affected tissue (26). Thus, a mutation involving GSH-S which rendered it susceptible to destruction by erythrocyte proteases, but not by proteases in other tissues, would be expressed only in the erythrocyte.

Erythrocyte glutathione deficiency may also rarely result from $\gamma$-glutamyl synthetase deficiency. We are aware of only a single reported case (27) with this defect.

A feature of glutathione deficiency that has not been described before is the marked decrease in the activity of erythrocyte GST. In developing an assay for this enzyme (28), we discovered that it was very rapidly denatured by the addition of one of its substrates, 1-chloro-2,4-dinitrobenzene. If GSH was added to the assay mixture before the addition of 1-chloro-2,4-dinitrobenzene, the enzyme was protected against destruction. It is reasonable to suppose that the xenobiotics that GST normally functions to conjugate to glutathione in vivo might have the same capacity to destroy the enzyme in the absence of GSH. Indeed, the younger erythrocytes of the patient, which contained some residual GSH, also had higher GST levels. It seems unlikely that GST deficiency represented a primary lesion in these patients. The activity of the enzyme in the parents was normal, and it is difficult to see how a deficiency of this glutathioneconjugating enzyme would result in a deficiency of glutathione.

\section{Acknowledgments}

We thank Dr. Tony Hugli for performing the 5-oxoproline estimations. This work was supported in part by grant HL 25552 from the National Institutes of Health, Division of Heart, Lung, and Blood.

\section{References}

1. Kosower, N. S., G. A. Vanderhoff, and I. M. London. 1967. The regeneration of reduced glutathione in normal and glucose-6-phosphate dehydrogenase deficient human red blood cells. Blood. 29:313-319.

2. Kosower, N. S., E. M. Kosower, and B. Wertheim. 1969. Diamide, 
a new reagent for the intracellular oxidation of glutathione to the disulfide. Biochem. Biophys. Res. Commun. 37:593-596.

3. Srivastava, S. K., Y. C. Awasthi, and E. Beutler. 1974. Useful agents for the study of glutathione metabolism in erythrocytes. Organic hydroperoxides. Biochem. J. 139:289-295.

4. Beutler, E. 1984. Red Cell Metabolism: A Manual of Biochemical Methods. Grune and Stratton, Inc., New York. Third ed.

5. Paniker, N. V., and E. Beutler. 1972. The effect of methylene blue and diaminodiphenylsulfone on red cell reduced glutathione synthesis. J. Lab. Clin. Med. 80:481-487.

6. Minnich, V., M. B. Smith, M. J. Brauner, and P. W. Majerus. 1971. Glutathione biosynthesis in human erythrocytes. I. Identification of the enzymes of glutathione synthesis in hemolysates. J. Clin. Invest. 50:507-513.

7. Foure-Seelig, G., and A. Meister. 1984. Gamma-glutamyl synthetase from erythrocytes. Anal. Biochem. 141:510-514.

8. Beutler, E., O. Duron, and B. M. Kelly. 1963. Improved method for the determination of blood glutathione. J. Lab. Clin. Med. 61:882890.

8a. Beutler, E., and T. Gelbart. 1985. Plasma glutathione in health and in patients with malignant disease. J. Lab. Clin. Med. 105:581-584.

9. Owens, C. W., and R. V. Belcher. 1965. A colorimetric micromethod for the determination of glutathione. Biochem. J. 94:705-711.

10. Tietze, F. 1969. Enzymic method for quantitative determination of nanogram amounts of total and oxidized glutathione: applications to mammalian blood and other tissues. Anal. Biochem. 27:502-522.

11. Vettore, L., M. C. De Matteis, and P. Zampini. 1980. A new density gradient system for the separation of human red blood cells. $\mathrm{Am}$. J. Hematol. 8:291-297.

12. English, D., and B. R. Anderson. 1974. Single-step separation of red blood cells, granulocytes and mononuclear leukocytes on discontinuous density gradients of ficoll-hypaque. J. Immunol. Methods. 5:249252.

13. Jellum, E., T. Kluge, H. C. Boerresen, O. Stokke, and L. Eldjarn. 1970. Pyroglutamic aciduria: a new inborn error of metabolism. Scand. J. Clin. Lab. Invest. 26:327-335.

14. Larsson, A., and R. Zetterstroem. 1974. Pyroglutamic aciduria (5-oxoprolinuria), an inborn error in glutathione metabolism. Pediatr. Res. 8:852-856.

15. Wellner, V. P., R. Sekura, A. Meister, and A. Larsson. 1974 Glutathione synthetase deficiency, an inborn error of metabolism in- volving the $\gamma$-glutamyl cycle in patients with 5-oxoprolinuria (pyroglutamic aciduria). Proc. Natl. Acad. Sci. USA. 71:2505-2509.

16. Hagenfeldt, L., A. Larsson, and R. Zetterstroem. 1974. Pyroglutamic aciduria. Studies in an infant with chronic metabolic acidosis. Acta Paediatr. Scand. 63:1-8.

17. Spielberg, S. P., L. I. Kramer, S. I. Goodman, J. Butler, F. Tietze, P. Quinn, and J. D. Schulman. 1977. 5-Oxoprolinuria: biochemical observations and case report. J. Pediatr. 91:237-241.

18. Boivin, P., C. Galand, and G. Schaison. 1978. Deficit en glutathion-synthetase avec 5-oxoprolinurie. Deux nouveaux cas et revue de la litterature. Nouv. Presse Med. 7:1531-1535.

19. Boxer, L. A., J. M. Oliver, S. P. Spielberg, J. M. Allen, and J. D. Schulman. 1979. Protection of granulocytes by vitamin $\mathrm{E}$ in glutathione synthetase deficiency. N. Engl. J. Med. 301:901-905.

20. Marstein, S., E. Jellum, B. Halpern, L. Eldjarn, and T. L. Perry. 1976. Biochemical studies of erythrocytes in a patient with pyroglutamic acidemia (5-oxoprolinemia). N. Engl. J. Med. 295:406-412.

21. Oort, M., J. A. Loos, and H. K. Prins. 1961. Hereditary absence of reduced glutathione in the erythrocytes: a new clinical and biochemical entity? Vox Sang. 6:370-373.

22. Boivin, P., and C. Galand. 1965. La synthese du glutathion au cours de l'anemie hemolytique congenitale avec deficit en glutathion reduit. Deficit congenital en glutathion- synthetase erythrocytaire? Nouv. Rev. Fr. Hematol. 5:707-720.

23. Mohler, D. N., P. W. Majerus, V. Minnich, C. E. Hess, and M. D. Garrick. 1970. Glutathione synthetase deficiency as a cause of hereditary hemolytic disease. N. Engl. J. Med. 283:1253-1257.

24. Spielberg, S. P., M. D. Garrick, L. M. Corash, J. D. Butler, F. Tietze, L. V. Rogers, and J. D. Schulman. 1978. Biochemical heterogeneity in glutathione synthetase deficiency. J. Clin. Invest. 61:14171420.

25. Beutler, E. 1976. Glutathione deficiency, pyroglutamic acidemia and amino acid transport. N. Engl. J. Med. 295:441-443. (Editorial).

26. Beutler, E. 1983. Selectivity of proteases as a basis for tissue distribution of enzymes in hereditary deficiencies. Proc. Natl. Acad. Sci. USA. 80:3767-3768.

27. Konrad, P. N., F. Richards, II, W. N. Valentine, and D. E. Paglia. 1972. Gamma-glutamyl-cysteine synthetase deficiency. $N$. Engl. J. Med. 286:557-561.

28. Harvey, J. W., and E. Beutler. 1982. Binding of heme by glutathione s-transferase: a possible role of the erythrocyte enzyme. Blood. 60:1227-1230. 